\title{
A CASA: CULTURA E SOCIEDADE NA EXPRESSÃO DO DESENHO INFANTIL ${ }^{1}$
}

Sonia Grubits*

RESUMO. Pesquisas sobre a identidade de crianças de periferia e de diferentes grupos indígenas nos indicaram a casa como tema freqüentemente escolhido nos trabalhos de expressão artística. Os estudos sobre o desenho, de um modo geral, favorecem investigações sobre o desenvolvimento infantil no que se refere à inteligência, à cognição, à motricidade e à afetividade, além da identificação de aspectos sociais e culturais do meio ambiente das crianças. Casas desenhadas por crianças Guarani/Kaiowá, em pesquisa sobre identidade, crianças Bororo, numa oficina de desenho e o estudo de caso de uma menina Kadiwéu revelaram as organizações sociais e importantes aspectos culturais dos referidos grupos indígenas.

Palavras-chave: desenho da casa; cultura; sociedade.

\section{THE HOUSE: CULTURE AND SOCIETY IN THE EXPRESSION OF CHILDREN'S DRAWING}

\begin{abstract}
Studies about the identity of children from city peripheral neighborhoods and indigenous groups showed us the house as a frequent chosen theme in works of artistic expression, in special drawing and paintings. The study of the drawing, by different authors, favors research about child development regarding intelligence, cognition, motility, and affectivity, besides the identification of social and cultural aspects of the children's context. Houses drew by Guarani/Kaiowá children, in a research about identity as well as the works of Bororo children at drawing workshops, and a case study of a Kadiwéu girl revealed the social organization and important aspects of these respective cultures.
\end{abstract}

Key words: house drawing; culture; society.

\section{POR QUE A CASA?}

O estudo de desenhos, em especial de desenhos infantis, tem sido objeto de nossas investigações sobre a construção da identidade, seja analisando o próprio desenho seja como recurso para avaliação dos resultados de nossas pesquisas.

$\mathrm{Na}$ primeira vez em que aplicamos desenhos em pesquisa, fizemos um trabalho de pré e pós-intervenção. Analisamos dez grupos de crianças de periferia, da faixa de 07 a 09 anos, que passaram por um processo de psicoterapia de um ano. Para este trabalho, criamos um critério quantitativo, selecionando dez itens relevantes nos desenhos da casa, árvore, pessoa e família, para verificar a maturidade emocional dessas crianças. Posteriormente, utilizamos o mesmo critério para comparações da referida população, com grupos infantis indígenas, inicialmente os Guarani/Kaiowá e mais recentemente os Kadiwéu.
Além desta aplicação, mais quantitativa, imediata e exploratória dos desenhos, trabalhamos com grupos menores, com atividades de expressão artística, em especial desenhos e pinturas, usando diferentes materiais.

Neste trabalho com desenhos e pinturas, um dos temas, a casa, chamou-nos a atenção pelo seu significado e representação, intimamente relacionados à cultura, sociedade, vida e tradição familiar e, finalmente, à identidade.

\section{O DESENHO INFANTIL}

Nossos estudos com desenhos sempre foram feitos em trabalhos de crianças. Por isso, para melhor fundamentar nossas reflexões sobre o desenho da casa, torna-se necessária uma revisão teórica de aspectos relevantes do grafismo no desenvolvimento infantil.

Apoio do CNPq.

Docente, doutora, coordenadora do Programa do Mestrado em Psicologia da Universidade Católica D. Bosco (UCDB), MS.

Endereço para correspondência: Av. Mato Grosso, n. 759, Centro, Campo Grande-MS. E-mail: sgrubits@uol.com.br 
Partindo de autores que procuraram analisar o significado do desenho e como ele se manifesta em diferentes etapas do desenvolvimento humano, em especial daqueles que estudaram o desenho da casa, pretendemos refletir sobre nossa experiência, a importância e significado do desenho da casa para a criança.

Segundo Widlöcher (1998), os desenhos infantis são objeto de nossa curiosidade porque não existe o desenho adulto. Se o adulto não é um artista, ele não desenha. Sua atividade gráfica é reduzida a alguns ensaios de caricaturas e rabiscos não figurativos. As crianças, no entanto, revelam, em relação aos desenhos, um tipo de conduta que parece próprio e espontâneo.

O desenho, em cada etapa da evolução das atitudes intelectuais, perceptivas e motoras das crianças, representa um compromisso entre suas intenções narrativas e seus meios. Trata-se, portanto, de um campo de estudos original da psicologia da criança.

A criança não toma cuidado com a aparência visual que permite reconhecer o objeto. Fiel, antes de tudo, à sua preocupação com o significado, ela faz igualmente uso de procedimentos que vão ao encontro do realismo visual. Se um detalhe invisível permite fazer um reconhecimento melhor do objeto, ele será representado contra toda a aparência.

Assim, a criança não hesita, no quadro de uma casa em que ela venha a desenhar a fachada, em representar o interior das peças que a compõem, seus habitantes nas respectivas tarefas familiares, os móveis, etc. Este fenômeno, conhecido como transparência, não merece, segundo Widlöcher (1998), esse nome, pois é uma vez o interior e uma vez o exterior que a criança representa, sem procurar combinar logicamente essas duas representações.

Widlöcher (1998) critica o termo realismo intelectual, dizendo que a preocupação da criança não é representar as coisas tais quais elas são, mas figurálas de maneira identificável. Todos os artifícios que utilizar visam a este fim de representatividade, especialmente a exemplaridade de detalhes e a multiplicidade de pontos de vista.

Em relação à evolução da criança em direção ao realismo visual, Luquet (1994) afirma que, para não desenhar senão aquilo que se vê, é preciso saber se livrar de todas as inferências intelectuais e esquecer o que se sabe. A criança não pode isolar esse ponto de vista. A partir do momento em que ela o faz, graças ao progresso de suas capacidades de atenção e de concentração, ela renuncia ao sincretismo do realismo intelectual e ingressa, então, na fase do realismo visual.

Wallon, Cambier e Engelhart (1990), buscando ilustrar a influência do meio nos trabalhos infantis, relatam um estudo feito há dez anos, no Nepal, por uma etnóloga, N. Bauthéac, cujo objetivo era aprender, pelas crianças, os fundamentos de sua sociedade. O recolhimento dos desenhos teve lugar no acaso dos caminhos, nas cidades, no curso das atividades cotidianas, fora das escolas em geral, salvo em Katmandou. Segundo as regiões estudadas, as tendências aparecem muito nitidamente nos desenhos, seja na sua grafia seja no seu simbolismo.

Os desenhos obtidos com crianças taru, aborígenes da região do Terai, celeiro agrícola ao norte do território indiano, mostram que a folha de papel é um espaço aberto e que ela se recobre em todos os sentidos, segundo a cultura e o meio ambiente em que a criança está inserida. As crianças taru, segundo Bauthéac, citada por Wallon e cols. (1990), reproduziram o esquema gráfico tradicional para fazer, nos desenhos de homens e animais, o apoio de dois triângulos, inspirando-se nas esculturas decorativas das casas taru.

Por outro lado, nos desenhos de crianças escolarizadas da região de Katmandou, a representação gráfica é toda feita conforme os modos ocidentais, com a mesma organização da página. A evolução da pessoa e da casa, segundo a autora, corresponde àquela das crianças francesas.

Nas vilas do vale do Langtang, a 4000m. de altura, num lugar onde as crianças vivem afastadas de outra civilização que não a sua, sem escola e sem imagem, os desenhos de 400 crianças são uma transmissão dos símbolos culturais pelos símbolos religiosos, como os objetos de oferenda e bandeiras sagradas.

As pesquisas relatadas e outros estudos, afirmam Wallon e cols. (1990), os leva a pensar que cada sociedade, cada grupo, exprime-se graficamente de maneira diferenciada e específica, sem excluir a existência de signos e de regras universais.

O desenho conta também, a quem pode entender, o que nós somos no momento presente, integrando o passado e nossa história pessoal. O desenho conta sobre o objeto; ele é a imagem do objeto e se inscreve entre numerosas modalidades da função semiótica: ilustrar, desenhar, fazer o sentido com os traços, quer dizer com outros sinais ou com as imagens de tais objetos, que são muitas vezes difíceis de dizer ou descrever com as palavras.

O desenho é um suporte onde se misturam e se cruzam os valores do objeto e os valores da pessoa. (Grubits \& Darrault-Harris, 2001). Ele é a concretização de um diálogo inconsciente, buscando conciliar as exigências do sujeito e aquelas do objeto, um diálogo que organiza o conhecimento e permite reduzir a distância entre o eu e o não-eu. 
A identificação e a legibilidade da produção são geralmente tributárias de uma semelhança visual, visão fotográfica com o objeto: a imagem desenhada aparece como uma transcrição, sobre a folha de papel, das qualidades sensíveis do objeto; ela reduz o real para melhor o evocar; ela é uma elaboração original, um agregado de significados, cuja natureza e estrutura são largamente determinadas pelos processos diversos, de ordem perceptiva, cognitiva e sociocultural; processos que, além disso, subentendem e trabalham a personalidade do desenhista.

Wallon e cols. (1990) alertam quanto aos riscos que corremos ao analisar o desenho, quando, para facilitar ou por falta de clareza, nossa atitude pragmática nos leva a esquecer as origens do desenho e a considerá-lo como objeto autônomo, sem nos preocuparmos inicialmente com as circunstâncias particulares e os processos que orientam sua produção.

Mais grave seria decompormos a imagem, isolar algum detalhe privilegiado, hierarquizá-lo e lhe atribuir um valor significativo específico. Além disso, o signo não adquire seu significado senão nas suas relações com a reunião de tudo aquilo a que ele pertence.

Esse procedimento é particularmente nefasto no caso de desenho da criança, onde o adulto é levado a isolar uma série de unidades significativas, definidas por um conceito de objeto que não corresponde necessariamente à concepção sincrética de uma criança. Em conseqüência, o desenho da criança tem muitas vezes sido analisado com referência a uma perspectiva adulta (adultóide) e a uma maneira de fazer valorizada pelo grupo social.

A qualidade da produção gráfica é legitimada por uma dimensão normativa e cultural; o desenho da criança é, desde então, descrito em termos negativos, em termos de ausência, de semelhança e de detalhes. Um exemplo disso está na maioria das escalas psicométricas, onde a argumentação de número de detalhes traduz uma melhor leitura (interpretação) do desenho e aparece como uma mais valiosa ordem intelectual.

Destarte, também os objetos não pertencem somente às classes de objetos, eles se definem nas suas relações com os outros objetos, segundo as leis que fazem do nosso universo um mundo de forças e relações. Assim o sol simboliza calor, vida e poder de fecundação. Em cada uma dessas relações, ele se encontra numa situação análoga à de outros objetos que igualmente simbolizam calor, ou vida, ou fecundação. Por um lado, ele se opõe à lua, astro noturno, mas por outro lado, ele se opõe, também, à terra que ele ilumina.

O mundo dos objetos também é, destarte, um mundo de símbolos. O domínio do imaginário, que tem uma grande parte na vida da criança, se exprime muito naturalmente nesses desenhos.

Finalmente, o valor narrativo do desenho tem sobretudo um significado simbólico. Ele nos mostra a maneira como a criança, através das coisas, vive os significados simbólicos que ela lhes atribui. É a reunião de seu mundo imaginário que se reflete no seu desenho. O que ela não pode nos dizer de seus sonhos, emoções, nas situações concretas, ela nos indica pelos seus desenhos.

As análises e interpretações são, portanto, melhores, não se nos contentamos em estudar um desenho isolado, mas quando procedemos a uma análise comparativa de uma série de desenhos de uma mesma criança, procurando os temas comuns.

\section{A CASA}

Em relação aos desenhos propostos no $\mathrm{HTPF}^{2}$, o tema pessoa faz um apelo ao reino animal, àquele da árvore, o reino vegetal e àquele da casa, o reino mineral.

Por pertencer a um material mineral rígido, irredutível, da matéria que a constitui, a casa aparece como representativa dos elementos mais fundamentais do ser, segundo Royer (1989), de sua própria essência, química, alquimia, e como tal, de sua natureza mais profunda, inata, inteira, de alguma forma, a pedra angular da personalidade.

Por outro lado, a casa é construída, elaborada, edificada pela mão do homem. No seu estado atual, sua concepção é o resumo de todas as aquisições efetuadas ao longo das diferentes etapas do desenvolvimento humano. Assim, também a criança é moldada a partir de seus instintos, educada, transformada por sua família, ambiente e cultura. A representação de uma casa, portanto, parece, muito particularmente, levar em conta as interações entre a natureza e a cultura, entre o inato e o adquirido, entre o indivíduo e a sociedade.

Royer (1989) afirma, na sua obra Le dessin d'une maison, que a casa constitui um arquétipo mais complexo, e por isso, mais difícil de interpretar, mais rico também de significados que os temas desenho da árvore e pessoa. A casa é o símbolo de todas as "peles" sucessivas que nos envolvem - o seio materno, corpos, família, universo - e que vão se encaixando e modelando.

Assim, desenhar uma casa é evocar o último ego que reside mais fundo, assim como suas relações com todos seus envelopes; é revelar as modalidades de sua pertença no mundo.

\footnotetext{
2 HTPF ou seja, house, tree, person and family, em português, casa, árvore, pessoa e família.
} 
Para a autora, a casa é o termo mais carregado de ressonância afetiva, mais capaz de desencadear tantas lembranças, tantos sonhos, tantas paixões: a casa da infância, a casa da família, a casa das férias, a casa dos sonhos matrimoniais, a casa de retiro, a última moradia.

Cada uma de nossas casas possui suas fragrâncias, corredores e portas secretas, espaços, recantos, alquimia, culinária, ruídos e silêncios, fogos e águas, luzes, penumbras assustadoras ou propícias aos desabafos.

A imagem da casa, alegre ou não, nos acompanha ao longo de nossa vida. Esse arquétipo ligado a nossa segurança, amores, posses, status social, está inscrito mais profundamente em nós, até na nossa parte primitiva e animal, como a concha para o caracol.

A etologia nos informa que um grande número de animais possui, como nós, uma casa com suas peculiaridades: a toca rudimentar escondida sob as moitas, ninhos cuidadosamente construídos, buracos com labirintos com múltiplas passagens, colmeias sofisticadas, etc. Em torno desses refúgios, o animal delimita um território, uma zona de jogo e de caça, que ele se reserva e que marca os limites graças ao odor pessoal de seus dejetos, reconhecido pelos outros membros de sua espécie, assim como pelos predadores. (Royer, 1989).

No curso de sua evolução, a habitação foi submetida a formidáveis transformações. Inicialmente escondido em grutas naturais, o homem foi pouco a pouco personalizando sua habitação troglodita, acumulando tesouros e projetando suas fantasias na decoração das paredes.

Durante milênios a casa é aquecida, iluminada, mobiliada e decorada, relacionando paralelamente conforto e estética. A casa familiar se diferenciou para satisfazer a coletividade. Ela se transforma em escola, prefeitura, palácio de justiça, prisão, loja, hotel, etc. Assim também, exaltando seus sonhos e ambições, o homem construiu pirâmides, templos, catedrais, arranha-céus e palácios.

Dessa forma o homem construiu suas casas à imagem de sua evolução. Royer (1989) afirma que também a criança, na pesquisa de sua identidade, desenha as casas.

\section{A CASA NOS GRUPOS INFANTIS INDÍGENAS}

Em nossas investigações com grupos indígena,s desde do início da década de 1990, reunimos trabalhos e informações sobre os Bororo de Mato Grosso e Guarani/Kaiowá, de Mato Grosso do Sul. Atualmente já possuímos pesquisas mais avançadas, porém com resultados preliminares sobre os Kadiwéu e estamos iniciando atividades com os Terena, ambos também de Mato Grosso do Sul. As reflexões e análises no presente artigo envolvem desenhos e estudos de crianças Bororo, Guarani/Kaiowá e Kadiwéu.

\section{ORGANIZAÇÃO DAS CASAS: CULTURA E SOCIEDADE}

Durante nossa pesquisa de 1997 a 2001, na reserva indígena de Caarapó, Mato Grosso do Sul, reunimos um material muito significativo nas quatro escolas da referida reserva. As crianças realizaram o HTPF, desenhos com lápis de cor, lápis-cera e finalmente com cola colorida.

As afirmações e reflexões sobre os desenhos das casas, no capítulo anterior, corroboram nossas conclusões e primeiras experiências de escolha dos sujeitos da pesquisa com o grupo infantil Guarani/Kaiowá. Assim, as casas se destacaram nos desenhos do HTPF e nas pinturas das crianças da Reserva de Caarapó, indicando três formas de expressão e representação muito significativas.

Percebemos claramente que algumas crianças fizeram opção por desenhos de casas ligadas por caminhos, de acordo com a tradição de referido grupo, reunindo as habitações pelo parentesco, no mesmo local (figura 1). Outro grupo desenhou casas isoladas, mantendo, porém, as características da arquitetura Guarani/Kaiowá (figura 2). Finalmente, outras representaram simplesmente casas como os padrões de desenhos comuns da maioria das crianças que freqüentam escolas, nos centros urbanos (figura 3).

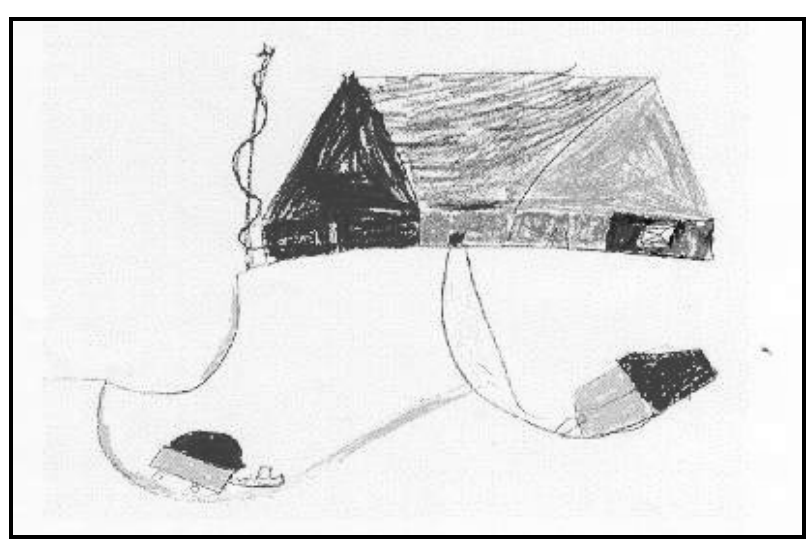

Figura 1. Casas com arquitetura Guarani, reunidas pelo parentesco.

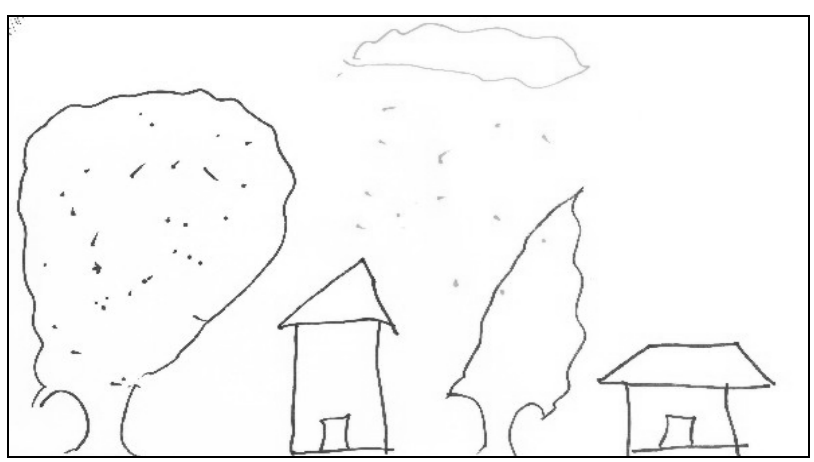

Figura 2. Casas com arquitetura Guarani isoladas. 


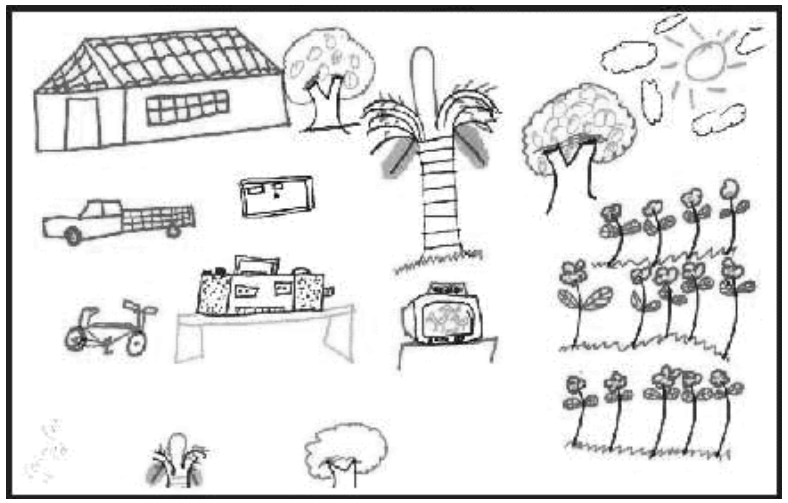

Figura 3. Casa com padrões de desenhos comuns das crianças da cidade.

Tendo em vista que a busca de identidade dessa população infantil - o que sobrevive da cultura indígena e o que vem se impondo na sociedade nacional envolvente - constituía o ponto fundamental na proposta de nossa pesquisa, achamos essa indicação valiosa para seleção dos sujeitos.

É importante ressaltar a estrutura do espaço onde vivem as famílias Guarani/Kaiowá, a representação da aldeia Guarani, segundo Viveiros Castro (1986), para entendermos a importância e significado dos desenhos das casas feitos pelas crianças (figura 4).

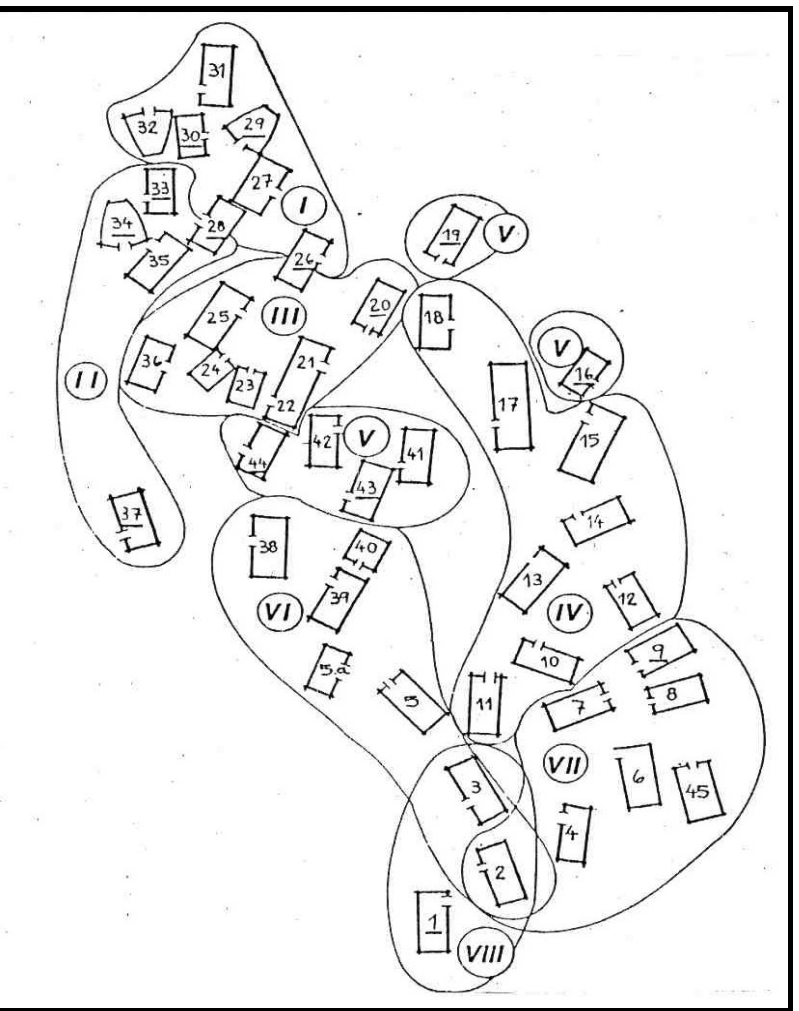

Figura 4. Representação da organização do espaço Guarani, segundo Viveiros de Castro (1986, p. 284).
O espaço onde vivem, segundo estudos de Viveiros de Castro (1992), Schaden (1974), Meliá (1990) e outros, envolve a significativa e peculiar relação do Guarani com a terra, que vai muito além do lugar para a morada e sobrevivência e de onde retiram o sustento através da agricultura.

A terra é, sobretudo, o tekohá, ou seja, o lugar onde se dão as condições de possibilidades do modo de ser do Guarani, o que envolve lei, cultura, comportamento, hábitos, religião, etc., que Pereira (1995) tão bem sintetizou como sendo um "espaço físico-político-simbólico, que remonta a mais um ato criativo dos deuses, lugar estruturante e suporte de sua organização social,(...) aí também circulam crenças, valores e normas" (p. 83).

Os desenhos de casas ligadas por caminhos, de acordo com a organização social Guarani (ver figura 1), representam, portanto, o tekohá, o espaço físicopolítico-simbólico, conforme fomos confirmando no estudo de caso da menina da referida etnia, descrito mais adiante.

Outra experiência semelhante ocorreu numa reserva Bororo, realizada numa oficina de desenho ${ }^{3}$ com giz de cera, com um grupo de 12 crianças, em 2002, em Meruri, Mato Grosso, onde aparece também, no desenho da casa, a representação da organização social do referido grupo étnico (figura 5).

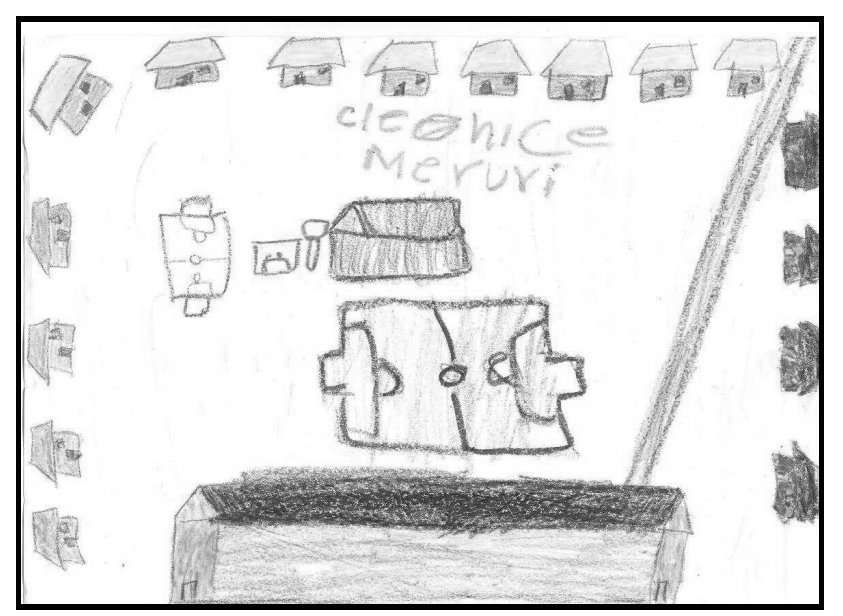

Figura 5. Trabalho de criança Bororo realizado numa oficina de desenho, em 2002.

$\mathrm{Na}$ concepção dos Bororo, a sociedade é organizada em aldeias formadas por um conjunto de choupanas tradicionalmente dispostas em círculo, em torno de uma grande choupana central, a casa dos

A oficina de desenho foi realizada pela acadêmica do $8^{\circ}$ semestre de Psicologia da UCDB Cibele Praça de Almeida Pinheiro. 
homens, bai mana gejewu ${ }^{4}$. A aldeia é dividida em duas metades pelo eixo leste-oeste, com as choupanas tugarege ao sul e choupanas ecerae ao norte, segundo Viertler (1976) (figura 6).

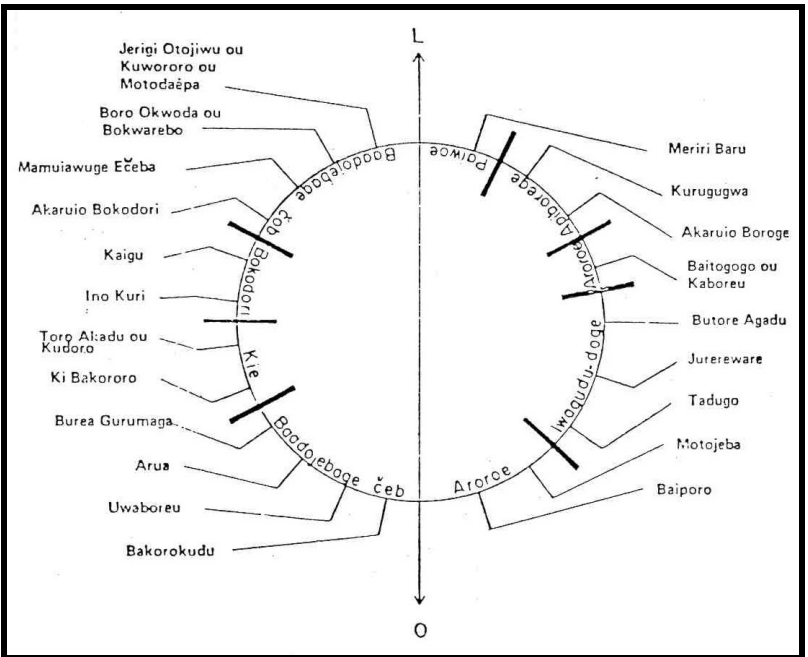

Figura 6. Organização das aldeias Bororo, segundo Viertler (1976, p. 151).

Na ocasião das primeiras visitas feitas a Meruri e Garça, para a execução da uma pesquisa, na década de 1990, observamos que alguns aspectos da cultura Bororo, como os descritos pelos autores Lévi Strauss (2000) e Viertler (1976), permaneciam como outrora, mas outros haviam sido modificados.

No Garça, aldeia que fica a trinta quilômetros de Meruri, constatamos que as casas dos índios eram construídas de palha e ainda dispostas em círculo, de acordo com a tradição Bororo. A organização das famílias permanecia e o bai mana gejewu era mantido, com suas atividades, no centro da aldeia (Grubits 1994).

Em Meruri, ao contrário, as casas eram de tijolo e a disposição delas não era circular, apesar da tentativa de que as fileiras formassem pelo menos um retângulo em torno do terreno central, onde existia uma estrutura que constituía uma tentativa de construção do bai mana gejewu (algumas estacas e cobertura de palha). Nem círculo nem o retângulo se completaram, mas, segundo os depoimentos dos moradores, ainda se tentava que as famílias mantivessem uma organização semelhante à tradicional (Grubits 1994).

4 Bai mana gejewu, casa dos homens, é uma construção localizada no centro do círculo, onde são realizados os rituais e funerais. Os homens sempre circulam na casa, porém as mulheres só podem entrar nas ocasiões especiais, quando ocorrem os referidos rituais e funerais.
Nos desenhos infantis Bororo realizados na oficina, em 2002, percebemos que nas representações, completas ou não, também ocorriam tentativas de manutenção da referida organização.

\section{ESTUDOS DE CASO: MENINO E MENINA GUARANI/KAIOWÁ, MENINA KADIWÉU}

Os estudos de caso do menino e menina Guarani/Kaiowá, assim como o da menina Kadiwéu, foram feitos a partir de desenhos, pinturas e outras técnicas expressivas, em grupos de cerca de seis crianças, nas duas reservas, numa média de quatro sessões mensais, durante nossas visitas de três dias.

Refletindo ainda sobre representação da casa e sua relação com a sociedade e cultura, em dois estudos de caso, percebemos também representações significativas. Uma menina Guarani/Kaiowá, num de seus desenhos com caneta hidrocor, num plano superior desenhou duas casas ligadas, de acordo com a representação tradicional Guarani/Kaiowá, mas as casas desenhadas são uma mistura de arquitetura indígena e casas semelhante às da cidade.

Além das casas, desenhou também árvores, um cachorro, o sol e nuvens. Ainda nesse nível, predominam as cores azul e amarela. No segundo, representou um ônibus, uma nuvem com chuva - mas sem nenhum desenho embaixo destas nuvens -, duas flores, uma árvore, uma casa com arquitetura dos desenhos da cidade, tudo no mesmo tamanho e nas cores vermelha e alaranjada.

Finalmente, no plano inferior, usando a própria borda do papel como linha de terra, desenhou, da esquerda para a direita, uma árvore e uma casa vermelha, uma flor verde e amarela, maior que a casa, um cachorro sem as patas traseiras e uma representação de chão sob suas patas, uma árvore azul, uma figura feminina em preto, uma outra casa e árvore, ambas em vermelho.

As casas ainda são uma mistura da arquitetura Guarani/Kaiowá com a casa da cidade. As árvores e a flor são maiores do que as casas. O cachorro e a figura feminina são menores do que os outros desenhos.

Nesse desenho, os três níveis estão bem-definidos, sendo que uma linha horizontal separa o segundo do terceiro de cima para baixo. No primeiro, sob o sol, com nuvens ao lado, aparece a representação das casas reunidas, um cachorro junto a uma árvore e mais adiante uma bananeira e depois da casa uma plantação (figura 7). 


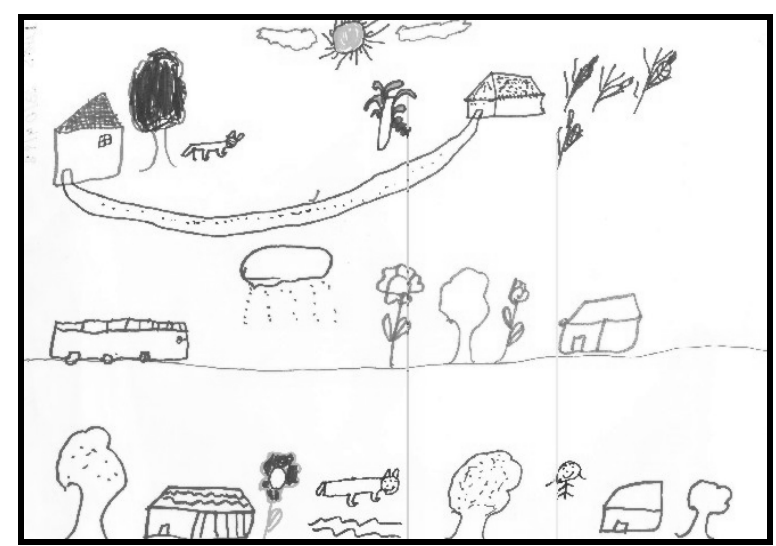

Figura 7. Desenho de uma menina Guarani/Kaiowá.

Cabe ressaltar que a casa aparece nos desenhos que, em análises semióticas posteriores, iriam nos indicar a representação dos três níveis (superior/céu; médio/terra, aldeia e inferior/mundo subterrâneo) da cosmologia Guarani. (Grubits \& Darrault-Harris, 2001)

No desenho da casa do menino Guarani/Kaiowá aparecem num mesmo plano, com a representação da linha de terra, da esquerda para a direita, um coqueiro muito colorido, uma casa com arquitetura das casas da cidade, porém com uma terceira parte, inclinada no lado direito, para o observador, o que não é comum nas referidas casas e nos indica discreta influência da arquitetura Guarani/Kaiowá, pois nesse caso, freqüentemente são representadas três partes de frente no desenho da casa, ou uma inclinação à esquerda e outra à direita (figura 8).

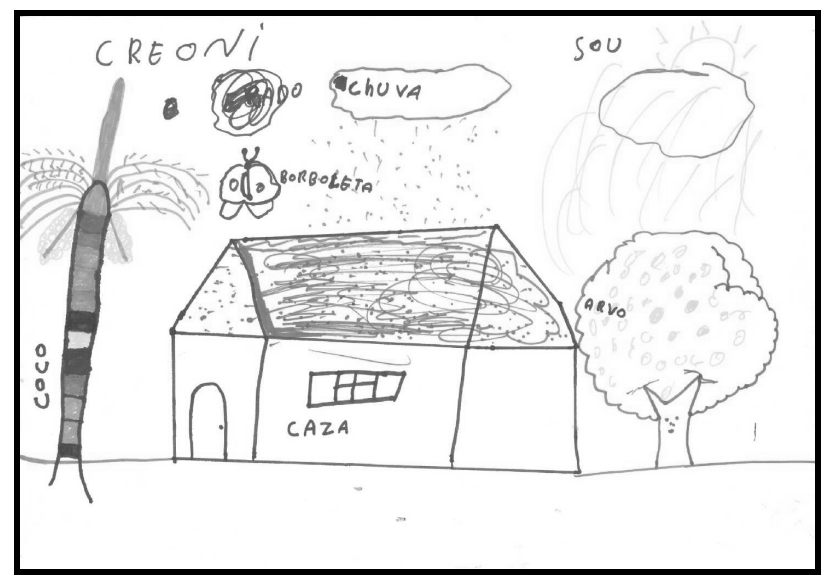

Figura 8. Desenho de um menino Guarani/Kaiowá.

O mesmo menino, no último desenho, após um ano de sessões regulares na Reserva de Caarapó, além da própria casa como casa da cidade, fez um caminhão, uma bicicleta, um aparelho de som numa mesa, uma TV em outra mesa, uma kodak, conforme ele denominou a máquina fotográfica (figura 3 ).

Todos esses aparelhos estão fora da casa, como se ele quisesse expor, ordenar os objetos de consumo da sociedade moderna, importantes na busca de sua identidade de homem da cidade. Desenhou também duas laranjeiras e uma outra árvore, o sol amarelo rodeado de nuvens, um coqueiro e várias flores, informando, porém, que eram da sua casa e não da reserva indígena.

Na trajetória das duas crianças, nos seus desenhos, pinturas, bricolagem e modelagem, observamos como a representação desse espaço, o tekohá, usando dos recursos dos conceitos fundamentais da semiótica como proxemique $^{5}$, destinador e antidestinador ${ }^{6}$, entre outros, nos conduziu a configuração de suas identidades.

Vejamos o caso da menina. Desde sua primeira pintura, ela começa a representar através de seus destinadores e destinatários conforme análise semiótica desenvolvida em pesquisa, que sempre são bons e satisfatoriamente organizados, quando intimamente ligado às forças da natureza, matas, roças; representa as casas ordenadas segundo a organização social tradicional Guarani.

Também é interessante ressaltar, como fato que demonstra a importância do trabalho realizado e a construção de sua identidade, tanto sob ponto de vista psíquico como social, da cultura e em especial da cosmologia Guarani, que ambas as crianças começaram do mesmo ponto, representando a cultura Guarani/Kaiowá e a sociedade nacional envolvente nos primeiros trabalhos, e no final optaram por uma delas.

A casa, nosso objeto de estudo desde a seleção das crianças, foi muito reveladora na trajetória de ambos. Apareceu indicando, para a menina, mais aspectos da cultura Guarani/Kaiowá e sua estrutura familiar, representada pela ligação de casa, ou um agregado de pequenas aldeias, bairros, de casas voltadas para si mesmas, conforme afirmou Schaden (1974, p. 59-60). Quanto ao menino, os desenhos das casas têm características semelhantes aos das crianças da cidade.

$\mathrm{Na}$ última sessão com o grupo da referida pesquisa, a menina representou somente a cosmologia e natureza (figura 9), o menino, com muito destaque, os aparelhos e viaturas que caracterizam o mundo moderno, ou seja, aquilo que é muito anunciado e pontuado na mídia de um modo geral (ver figura 3 ).

\footnotetext{
Proxémique, de acordo com Greimás e Courtés (1993), é um projeto da disciplina Semiótica que busca analisar as disposições dos sujeitos e dos objetos no espaço, mais particularmente, o uso que os sujeitos fazem para fins de significação. A proxémique cobre, em parte, a Semiótica do Espaço, mas também a Semiótica Natural, Semiótica Teatral, Semiótica Discursiva, etc.

6 Segundo Darrault-Harris e Klein (1993), dada a estrutura polêmica da narrativa, a presença de um sujeito e de um anti-sujeito pressupõe a existência de um destinador (D1) e de um antidestinador (D2).
} 


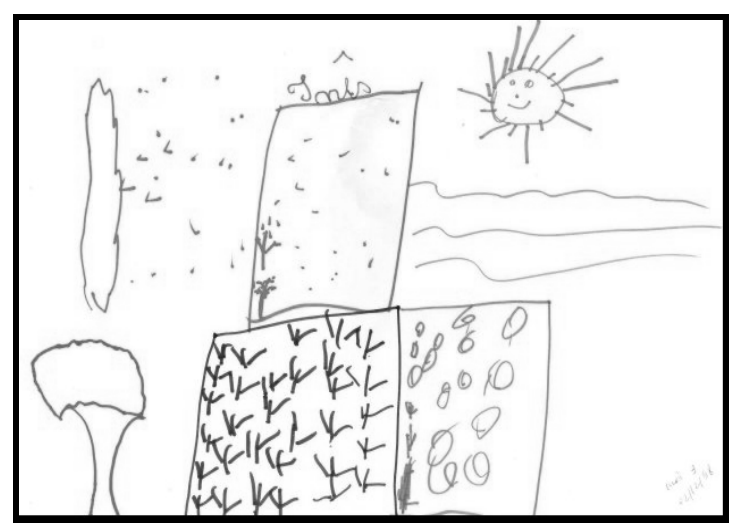

Figura 9. Desenho de uma menina Guarani/Kaiowá, representando a cosmologia Guarani.

Atualmente estudamos os Kadiwéu, também conhecidos como Guaicuru, índios cavaleiros, ceramistas famosos, com cores e desenhos característicos, de acordo com o grupo familiar, segundo relato de informantes. Como nos estudos citados por Wallon e cols. (1990), as meninas decoraram as casas com motivos de tais cerâmicas e tradição familiar (figura 10).

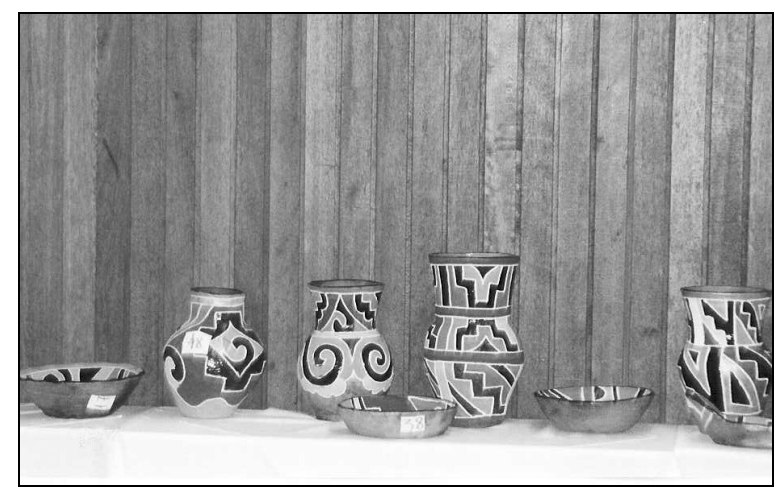

Figura 10. Cerâmica Kadiwéu.

A seqüência de desenhos de uma menina do grupo traz a representação da decoração Kadiwéu, que tradicionalmente se refere à mulher ceramista, na fachada de duas casas e nas flores representadas (figura 11).

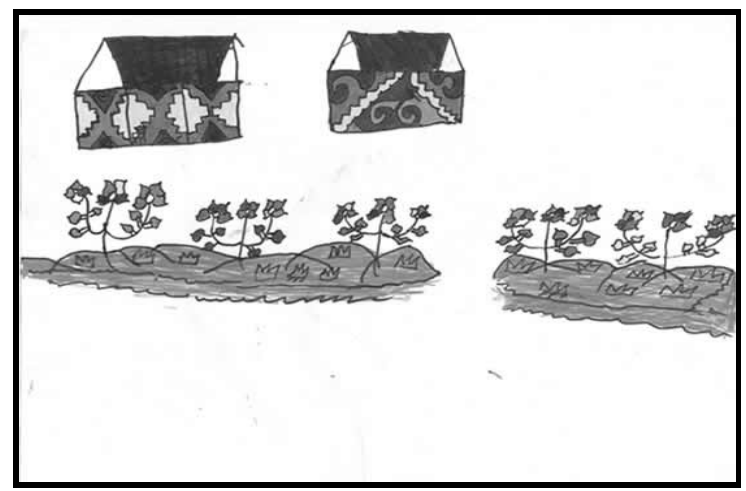

Figura 11. Trabalho de uma menina Kadiwéu, mantendo cores e desenhos das cerâmicas da referida etnia, na fachada das casas.
Em outro trabalho da mesma menina Kadiwéu aparecem cores e desenhos das cerâmicas da referida etnia, não só na fachada das casas, mas também nas plantas e no animal desenhado (figura 12).

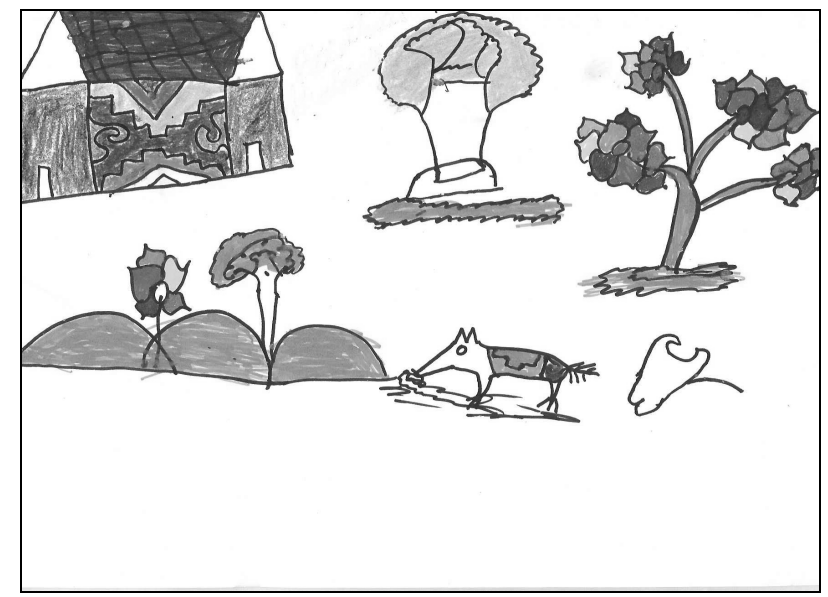

Figura 12. Trabalho de uma menina Kadiwéu, com cores e desenhos das cerâmicas, não só na fachada das casas, mas também nas plantas e no animal desenhado.

Os homens não são ceramistas, trabalham mais na pecuária e caça. Um dos trabalhos de um menino Kadiwéu serve como ilustração dos temas, cores e desenhos escolhidos pelos meninos. A casa, os dois animais silvestres, uma anta e um tatu, assim como um boi, não são coloridos (figura 13).

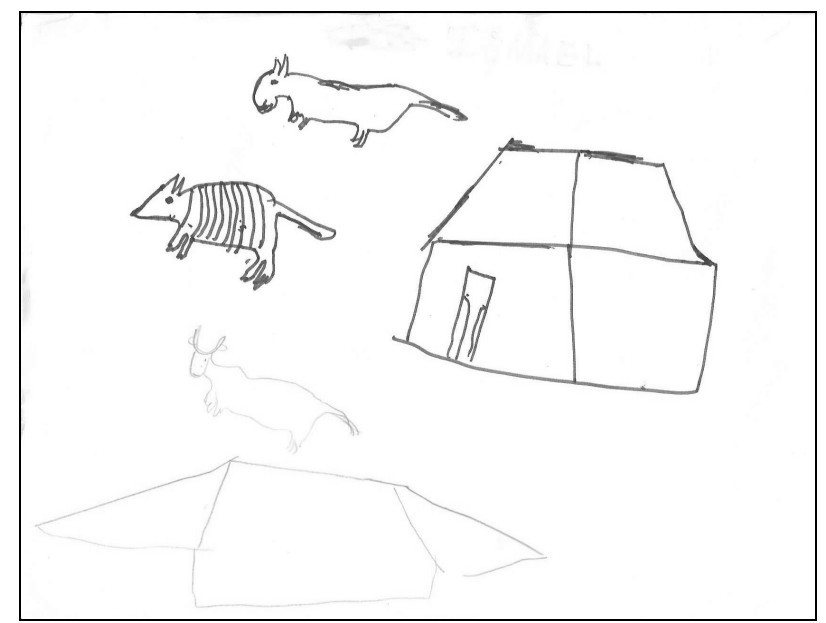

Figura 13. Trabalho de um menino Kadiwéu.

As diferenças são muito relevantes e apareceram nos desenhos, em especial a casa da menina Kadiwéu. As questões de gênero e cultura vêm sendo confirmadas nas pesquisas que estamos desenvolvendo com o referido grupo étnico.

Cabe ressaltar, mesmo sem termos chegado à discussão final da pesquisa, que a construção da identidade Kadiwéu na análise destes trabalhos aparece 
sem conflitos ou contradições em relação à sociedade nacional envolvente.

\section{CONCLUSÃO}

Nossos relatos e pesquisas conduzem a reflexões sobre o tema universal casa, sempre presente no desenho infantil, expressão de aspectos culturais, sociais e psicológicos vivenciados pelas crianças.

Tanto nas representações nos trabalhos da primeira pesquisa com crianças Guarani/Kaiowá de Caarapó quanto nos trabalhos da oficina de desenho com crianças Bororo, a casa foi representada de acordo com as respectivas culturas.

Assim também, nos dois estudos de caso, de um menino e uma menina Guarani/Kaiowá e uma menina Kadiwéu, foi possível perceber nos desenhos, em especial no da casa, a construção da identidade infantil, nas contradições de ser ou não um indígena do grupo em questão.

Em cada uma das experiências relatadas, as crianças de cada grupo expressaram-se graficamente de maneira diferenciada e específica, sem excluir a existência de signos e de regras universais.

No desenho da casa conferimos um sentido com os traços, ou seja, com sinais ou com as imagens comunicando o que muitas vezes é difícil de dizer com as palavras. Podemos, portanto, afirmar que o desenho da casa é um suporte onde se misturam e se cruzam os valores do objeto e os valores da pessoa, no momento presente, integrando o passado e a história pessoal, com aspectos sociais e culturais propriamente ditos.

\section{REFERÊNCIAS}

Darrault-Harris, I., Klein, J. (1993). Pour une psychiatrie de l'ellipse. Paris: Presses Universitaires de France.

Greimás, A. J., Courtés, J. (1993). Sémiotique, dictionnaire raisonné de la théorie du langage. Paris: Hachette Livre.

Grubits, S. \& Darrault-Harris, I. (2001). Psicossemiótica na construção da identidade infantil: um estudo da produção artística de crianças Guarani/Kaiowá. São Paulo/Campo Grande: Casa do Psicólogo/Universidade Católica Dom Bosco.

Grubits, S. \& Darrault-Harris, I. (2001). Transculturalité et représentation de l'espace chez les Guarani-Kaiowá du Brésil. The Journal of the International Association for Visual Semiotics, 6 ,(2-3), 45-53.

Grubits, S. (1994). Bororo: identidade em construção. Campo Grande: Departamento Gráfico do Colégio Dom Bosco.

Lévi-Strauss, C. (2000). Tristes trópicos. São Paulo: Companhia das Letras.

Luquet, G. (1994). Le dessin enfantin. Paris : PUF.

Meliá, L. B. (1990) A terra sem mal dos Guarani. Revista de Antropologia, 33, 33-46.

Pereira, M. A. da C. (1995) Uma rebelião cultural silenciosa. Funai.

Royer, J. (1989). Le dessin d'une maison: image de l'adaptation sociale de l'enfant. France: EAP Editions.

Schaden, E. (1974). Aspectos fundamentais da cultura Guarani. (3 ${ }^{\text {a }}$ ed.) São Paulo: Editora da Universidade de São Paulo.

Viertler, B. R. (1976). As aldeias Bororo: alguns aspectos de sua organização social. (Coleção Museu Paulista, Série Etnologia, Vol 2) São Paulo: Edição do Fundo de Pesquisas do Museu Paulista da USP.

Viveiros de Castro, E. B. (1986). Araweté, os deuses canibais. Tese de Doutorado apresentada ao Programa de Pós Graduação em Antropologia Social do Museu Nacional da Universidade Federal do Rio de Janeiro. Rio de Janeiro: Zahar.

Viveiros de Castro, E. B. (1992). Araweté: o povo do Ipixuna. São Paulo: CEDI.

Wallon, P., Cambier, A., Engelhart, D., (1990). Le dessin de l'enfant. France: Press Universitaires de France.

Widlöcher, D. (1998). L'interprétation des dessins d'enfants. France: Pierrre Mardaga éditeur.

Recebido em 05/04/2003

Revisado em 28/08/2003

Aceito em 10/09/2003

O arquivo disponível sofreu correções conforme ERRATA publicada no Volume 8 Número 2 da revista. 